\title{
READY MIXED CONCRETE CONSTITUENT MATERIALS; PLASTICIZING CHEMICAL ADMIXTURES AND EFFECTS ON FRESH AND HARDENED PROPERTIES
}

\author{
Evren ARIÖZ 1, *, Ömer ARIÖZ ${ }^{2}$ \\ ${ }^{1}$ Department of Chemical Engineering, Faculty of Engineering, Eskişehir Technical University, Eskişehir, Turkey \\ ${ }^{2}$ Department of Civil Engineering, Faculty of Engineering, Hasan Kalyoncu University, Gaziantep, Turkey
}

\begin{abstract}
The effects of plasticizing admixtures on the properties of fresh and hardened ready mixed concrete were studied. Eight different concrete mixtures were designed by two different polycarboxylate based plasticizing admixtures, CEM III/42,5 N type Portland cement, ground granulated blast furnace slag, natural sand, crushed limestone, and water. Flow ability of the freshly mixed concretes were measured and the compressive strength tests were carried out on $150 \mathrm{~mm}$ cubic specimens at the ages of 7 and 28 days. It was observed that flow values increased when the amount of admixture used in the mixtures increased. The composition of the admixture affected the flow values of the mixtures significantly. Compressive strength test results revealed that the increase in amount of slag in the amount of total binding material resulted in lower 7-days strength values. Type of chemical admixtures significantly influenced the 7-days strength values. This was attributed to the different secondary effects of different plasticizing chemical admixtures. Type of chemical admixture influenced both 7-days strength and 28-days strength even the mixtures had equal amounts of ingredients and also equal water/binder ratios. This result showed that plasticizing chemical admixtures can affect both early and later age strengths of ready mixed concrete even for equal water/binder ratios.
\end{abstract}

Keywords: Ready mixed concrete, Plasticizing chemical admixture, Flow ability, Compressive strength

\section{INTRODUCTION}

Ready mixed concrete (RMC) is a widely used construction material produced by mixing together cement, water, fine and coarse aggregate and if required chemical admixtures, mineral admixtures, and in some cases fibers in an automated mixers and then delivered to the customer in fresh state [1]. When cement is mixed with water, the resultant material is called cement paste and if fine aggregate is added to that mix, the material is named as mortar. When coarse aggregate is added to the mortar, the material becomes concrete [1,2]. Figure 1 presents the formation of cement paste, mortar, and concrete. In ready mixed wet mix production, the constituent materials are mixed together by means of automated systems [1].

Cement, water, and aggregate are main constituents and chemical admixtures, mineral admixtures, and fibers are optional ingredients of RMC. However, it should be marked that the use of chemical admixtures, mineral admixtures, and fibers is widespread because many benefits can be obtained by their application. For instance, chemical admixtures such as plasticizers modify the workability of the fresh mixture, mineral admixtures such as fly ash and ground granulated blast furnace slag (GGBFS) can improve the durability of hardened ready mixed concrete. Fibers can develop the toughness and tensile characteristics of hardened ready mixed concrete [1].

*Corresponding Author: evrenbayram@eskisehir.edu.tr

Received: 01.07.218 Accepted: 19.10.2018 


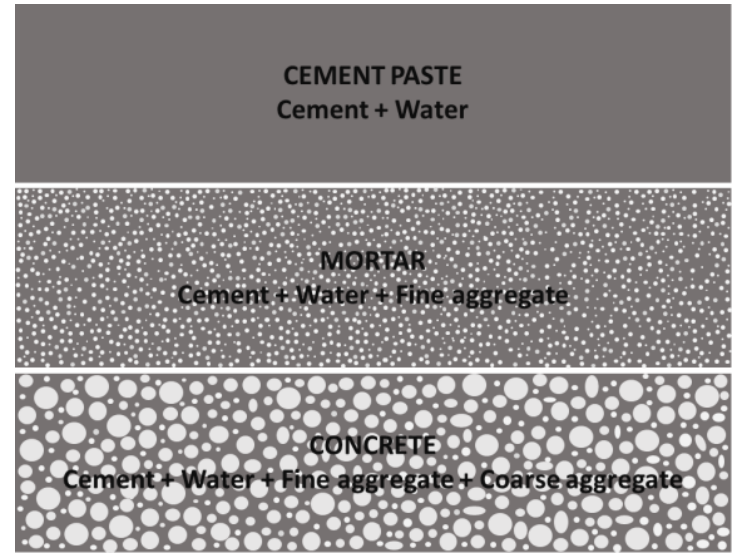

Figure 1. Formation of cement paste, mortar, and concrete

The function of hardened cement paste formed by reaction between cement and water is to hold aggregate particles together [1]. Water is necessary for the reaction between cement particles and water. Mixing water has two functions in the mixture; to react with cement and to give fluidity to the mixture for placing. Therefore the amount of water used in the mix is usually much higher than required for chemical reaction [2]. Aggregates occupy approximately $75 \%$ of the volume and influence significantly stiffness, unit weight, and strength of RMC [1,2]. It should also be noted that they fill the matrix economically. Figure 2 shows the basic functions of constituent materials of RMC [1].

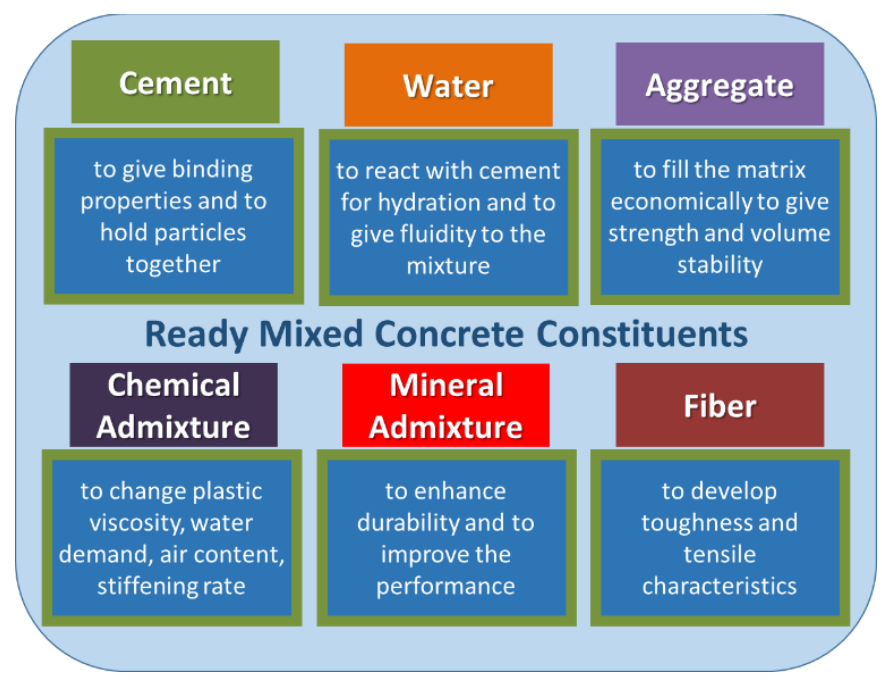

Figure 2. RMC constituent materials and their basic functions

\section{PLASTICIZING CHEMICAL ADMIXTURES FOR RMC}

Chemical admixtures for RMC are added to batch immediately before or during mixing operation in order to improve or modify the some fresh and hardened properties such as workability, workability retention, strength and durability. The main reasons to use chemical admixtures in the production of RMC are reducing the costs, retaining RMC quality during mixing, transporting, and placing especially in extreme weather conditions, and overcoming some difficulties faced during concreting operations $[1,3]$. Plasticizers are the most widely used chemical admixtures in RMC production. Placing properties of RMC can be improved by using plasticizing admixtures without changing the water/cement ratio of the mixture [4]. Plasticizing admixtures are also called as water reducers which can reduce the water demand of the mix when plasticity of RMC is kept constant. Reduction of mixing 
water for the constant workability level increases the strength [2]. Figure 3 summarizes the reasons for the use of plasticizers in RMC production [1].

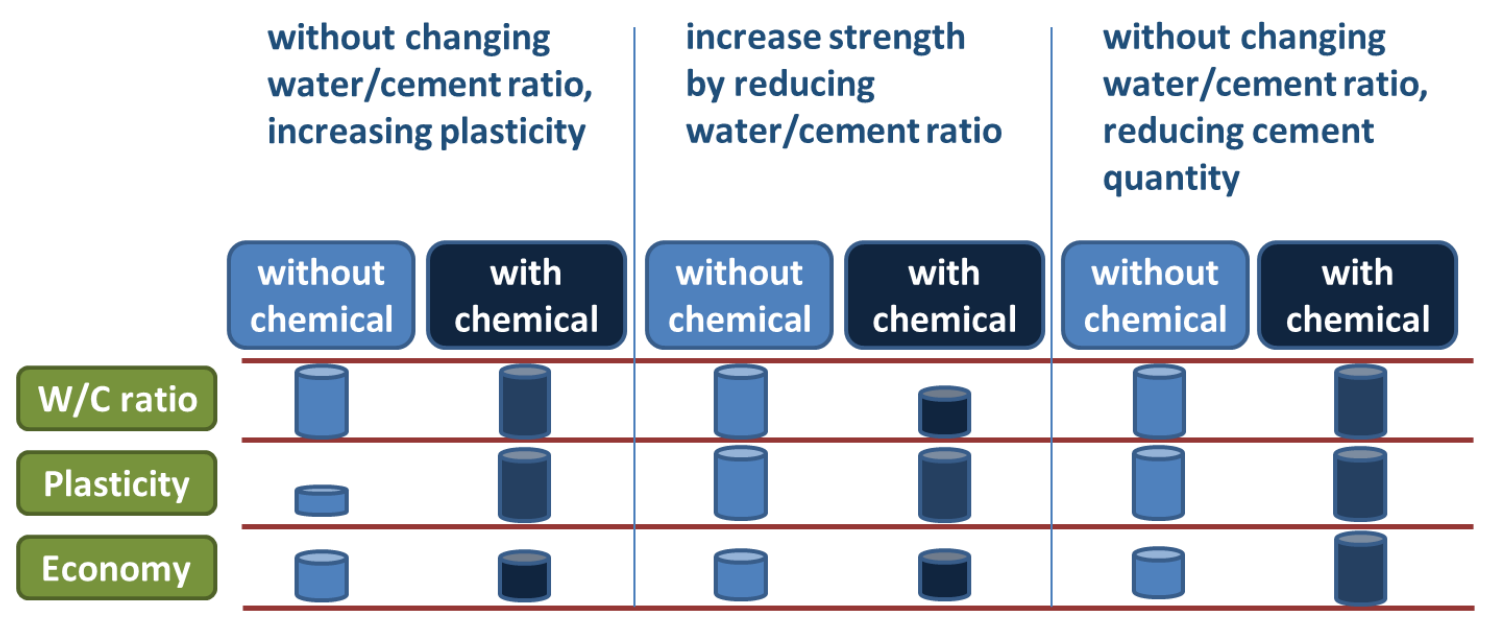

Figure 3. Reasons for the use of plasticizers in RMC production

Water reducers are divided into two categories as normal range water reducers (NRWR) and high range water reducers (HRWR) which are called as plasticizers and superplasticizers, respectively [1]. Normal range water reducers can reduce water requirement by $5-10 \%$ while high range water reducers can reduce water requirement by 15-40\%. Lignosulfonate salts of sodium and calcium are examples of normal range water reducers. Sulfonated naphthalene formaldehyde (SNF) and polycarboxylic ether (PCE) are examples of the high range water reducers. Lignosulfonates, sulfonated naphthalene formaldehyde condensates and polycarboxylic ether are regarded as $1 \mathrm{st}$, 2nd, and 3rd generation water reducing admixtures, respectively [2].

\subsection{Mechanism of Plasticizing Chemical Admixtures}

The plasticizing mechanism is different for different admixtures. Lignosulfonates and sulfonated naphthalene formaldehyde (SNF) based dispersants lower zeta potential leading to electrostatic repulsion which separates cement grains from flocculation. This will result in release of the entrapped water by cement grain clusters. Plasticizing admixtures produced from polycarboxylic ether include polymers with backbone and side chains. The backbones of the polymer are adsorbed on the surface of the cement grains, and the side chains cause dispersion of cement grains by the mechanism of steric hindrance. In other words, bulky side chains separate admixture molecules from each other [2]. Plasticizing (dispersing) admixtures adsorb onto the surface of the cement grains and break up the cement clusters, making easier individual cement particles to roll over each other. This allows to produce a more fluid mixture [5]. Figure 4 indicates effect of dispersing admixtures on fluidity of freshly mixed RMC schematically [1].

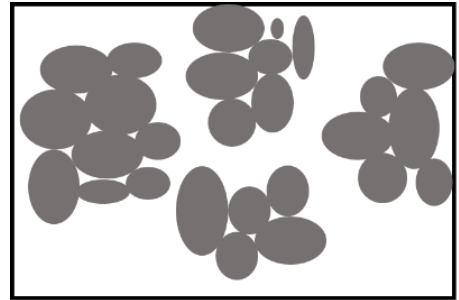

Low fluidity

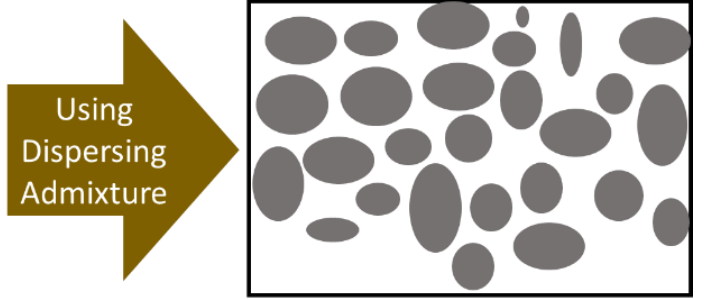

Improved fluidity

Figure 4. Effect of dispersing admixtures on fluidity of freshly mixed RMC 
The effectiveness of the chemical admixtures are dependent on the type and amount of cement and binding materials, the quantity of mixing water, shape and particle distribution of aggregate, mix proportions, temperature, slump value, and mixing duration of RMC [1,6]. The mixing water in RMC mixture is used for two main purposes; to make reaction with cement giving binding property and to give workability to the mixture. Table 1 lists basic constituents of RMC and their quantities [5].

Table 1. Basic constituents of RMC and their quantities.

\begin{tabular}{lcc}
\hline Constituents & $\begin{array}{c}\text { by weights } \\
(\boldsymbol{\%})\end{array}$ & $\begin{array}{c}\text { by volume } \\
(\boldsymbol{\%})\end{array}$ \\
\hline Cement & 15 & 11 \\
Water - required for hydration & 3 & 8 \\
Water - additional - to give workability & 5 & 11 \\
Aggregate & 77 & 70 \\
\hline
\end{tabular}

It should be marked that the additional water which will not react with cement but to give workability is $11 \%$ by volume. This additional water results in formation of capillaries that will reduce the strength and lower the durability of hardened RMC. Therefore, use of water-reducing admixtures makes enable to produce stronger and more durable material lowering the volume of this free water [5].

Freshly ready mixed concrete behaves as yield stress fluids [7]. Rheology of RMC can be defined as both the plastic deformation and flow of RMC. The rheology of a RMC mixture is determined by concrete making materials and the mix design. Rheology of RMC has two parameters; yield stress related to slump value and plastic viscosity related to cohesion of the mixture. When water content of the mixture is increased, both yield stress and plastic viscosity reduce and this increases the slump but the mixture is more susceptible to bleeding and segregation. As the mix is getting richer, yield stress reduces but plastic viscosity increases. Dispersing admixtures reduce the yield however they may increase or decrease plastic viscosity of the mixture depending on the secondary effects of the admixture [5]. Figure 5 illustrates the effects of constituent materials on the rheology of RMC [1].

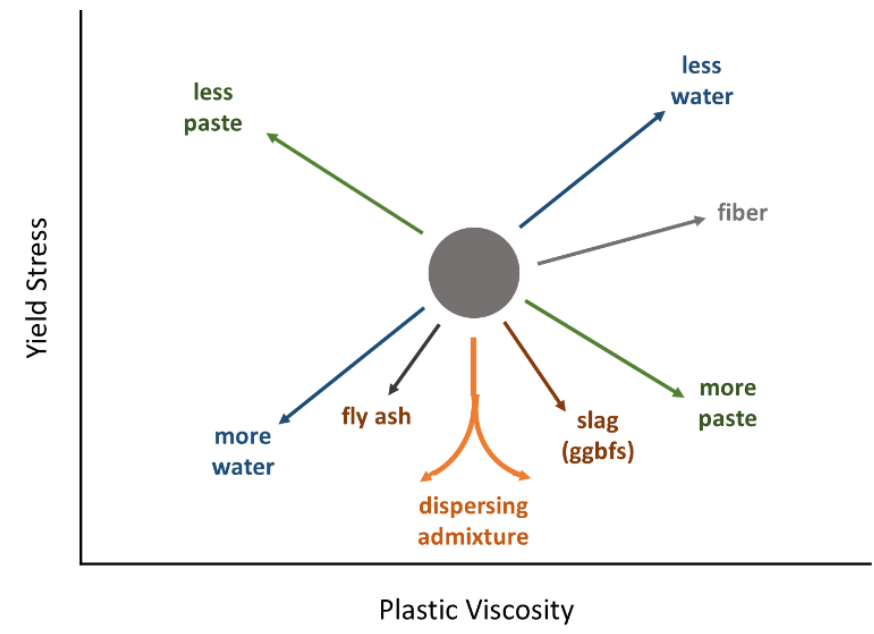

Figure 5. Effects of constituent materials on the rheology of RMC

\subsection{Chemical Structure and Mechanism of Poly carboxylate Based Dispersing Admixtures}

Polycarboxylate ethers (PCE) are new generation chemical admixtures used in RMC industry [2,5]. PCEs are group of products having generally different chemical structures [5]. Polycarboxylic ether is obtained by means of a polymerization process including a free radical mechanism with initiators. They consists of a backbone with side chains [2]. Structure of PCE may change for the specific purposes to make tailored product. Therefore the backbone length, the number and length of side 
chains may differ for different PCE molecules [1,2]. Figure 6 shows examples of different structures of PCE [1]. PCEs may have different chemical structures. A typical PC structure is shown in Figure 7 [5].

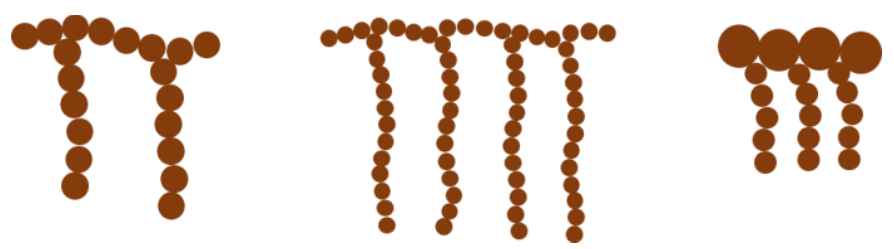

Figure 6. Examples of Different Structures of PCEs

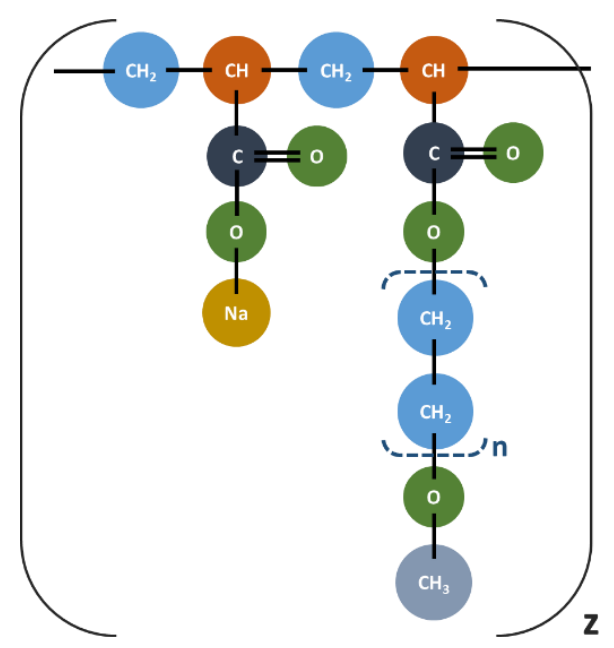

Figure 7. A typical PC structure

The backbone polymer is obtained by the polymerization of acrylic acid. This polymer can be used to arrange the number of carboxylate groups which are neutralized taking on a negative charge in solution when the $\mathrm{Na}+$ dissociates. This provides the connection point for adsorption of the mixture to the cement surface. The co-polymer is a polyether shown here as polyethylene glycol $(-\mathrm{CH} 2-\mathrm{CH} 2-\mathrm{O}-$ )n. The number of polyether groups defines the behavior of the admixture giving different properties. This makes enable copolymer to be tailored for different purposes such as high early strength and retention of workability of the fresh mixture.

In the dispersing mechanism of chemical admixtures, the negative charges on the admixture are adsorbed onto the positive charges on the calcium ions on the cement surface and there are two main mechanism for cement dispersing chemical admixtures; electrostatic repulsion and steric hindrance. Electrostatic dispersion is the mechanism of sulphonated naphthalene formaldehyde (SNF) and sulphonated melamine formaldehyde (SMF) based superplasticizers [5]. In PCE based superplasticizing admixtures, the polyether is responsible for the breaking the flocculation between the cement grains and works by a steric effect $[2,5]$.

Effectiveness of steric hindrance is higher than that of electrostatic repulsion. Steric hindrance of the side chains provide dispersion of the cement grains by migrating polyethylene oxide in water [2]. PCE molecules consists of - $\mathrm{COONa}$ groups which dissociate $\mathrm{COO}$ - and $\mathrm{Na}+$ in water. The $\mathrm{COO}$ - is still attached to the admixture due to the negative charge on. The polyether groups move away from the surface of the cement grains, resisting to approach the polyether chains attached to an adjacent cement grain, separating the two grains from each other [5]. Figure 8 shows dispersing mechanism of PCE based superplasticizers by steric hindrance schematically. 

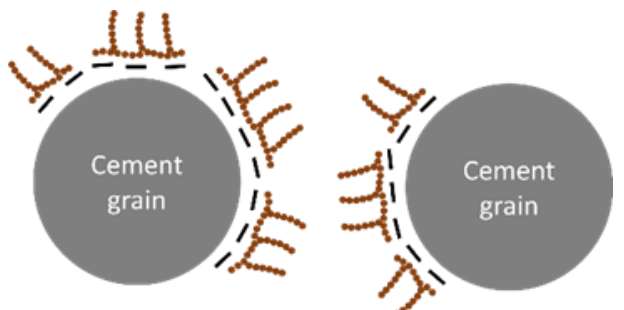

Figure 8. Dispersing mechanism of PCE based superplasticizers by steric hindrance

\section{EXPERIMENTAL STUDY}

The effects of plasticizing admixtures on the properties of fresh and hardened ready mixed concrete were studied. Eight different concrete mixtures were designed by two different polycarboxylate based plasticizing admixtures, CEM III/42,5 N type Portland cement, ground granulated blast furnace slag, natural sand, crushed limestone, and water. According to TS EN 197-1:2012 which is the standard related to composition, specification and conformity criteria for common cements, CEM III is produced by using blast furnace slag [8]. However, additional blast furnace slag was utilized in the mixtures since the study included the selection of ingredients of RMC mixes to be considered for the huge foundation of an infrastructure in case of hot weather casting operation. The maximum size of the coarse aggregate was $16 \mathrm{~mm}$. The properties of the aggregate were determined according to relevant standards TS EN 933-1:2012(EN) and TS 706 EN 12620+A1 [9,10]. The Figure 9 presents particle size distribution of aggregate part used in the mixtures.

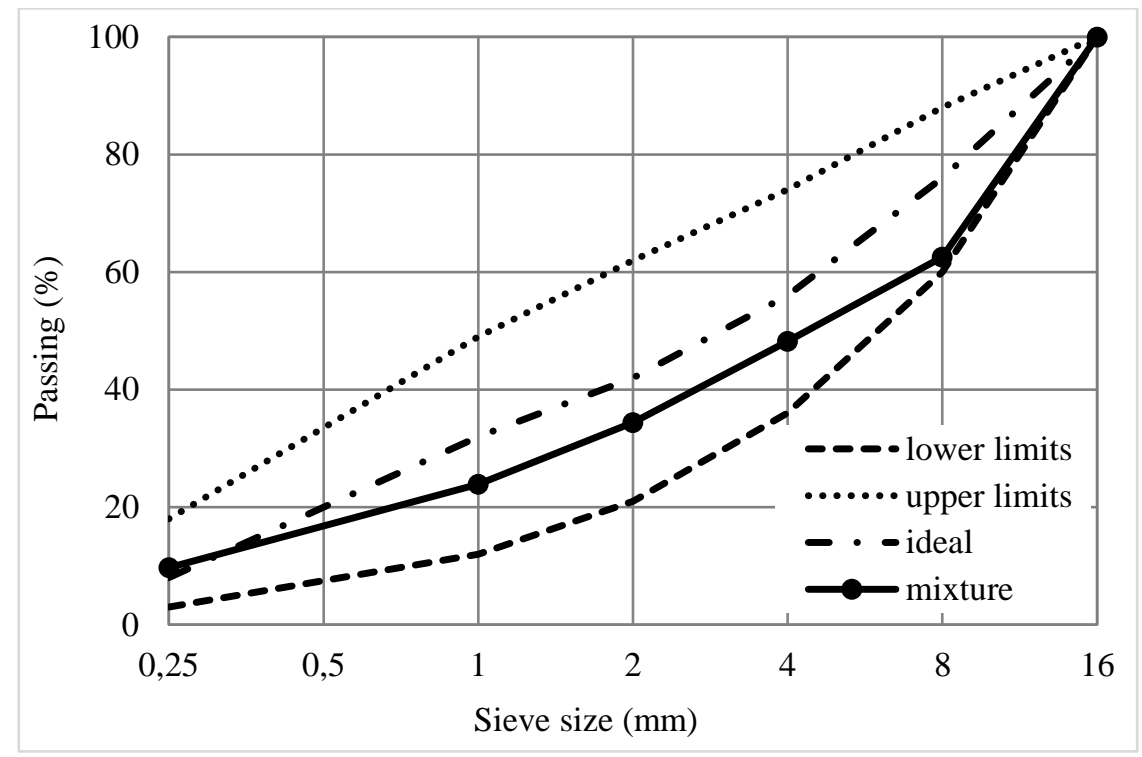

Figure 9. Particle size distribution of the aggregate

The two different plasticizing chemical admixtures used in the production of concrete samples were denoted as PC1 and PC2. For PC2 slightly different chemical admixtures were prepared and they are named as PC2A, PC2B, and PC2C. Mix designs of concretes were carried out according to relevant standard, TS 802 [11]. Table 2 shows the mix proportions and some features of different concrete mixtures. 
Table 1. Mix proportions and some features of different concrete mixtures

\begin{tabular}{|c|c|c|c|c|c|c|c|c|}
\hline $\begin{array}{l}\text { Materials and } \\
\text { Mixes }\end{array}$ & Mix-A & Mix-B & Mix-C & Mix-D & Mix-E & Mix-F & Mix-G & Mix-H \\
\hline $\begin{array}{l}\text { Cement }(\mathrm{kg}) \\
\text { Slag }(\mathrm{kg}) \\
\text { Water }(\mathrm{kg}) \\
\end{array}$ & $\begin{array}{c}340 \\
50 \\
166 \\
\end{array}$ & $\begin{array}{c}300 \\
90 \\
166 \\
\end{array}$ & $\begin{array}{c}300 \\
90 \\
166 \\
\end{array}$ & $\begin{array}{l}230 \\
190 \\
166 \\
\end{array}$ & $\begin{array}{l}230 \\
190 \\
166 \\
\end{array}$ & $\begin{array}{l}280 \\
170 \\
164 \\
\end{array}$ & $\begin{array}{l}280 \\
170 \\
164 \\
\end{array}$ & $\begin{array}{l}170 \\
230 \\
165 \\
\end{array}$ \\
\hline $\begin{array}{l}\text { Plasticizing } \\
\text { Chemical } \\
\text { Admixture (kg) }\end{array}$ & 4.29 & 4.10 & 3.71 & 5.25 & 4.20 & 6.08 & 6.08 & 6.20 \\
\hline $\begin{array}{l}\text { Natural Fine } \\
\text { Aggregate }(\mathrm{kg})\end{array}$ & 217 & 217 & 217 & 217 & 217 & 215 & 215 & 216 \\
\hline $\begin{array}{l}\text { Crushed Fine } \\
\text { Aggregate }(\mathrm{kg})\end{array}$ & 911 & 911 & 911 & 911 & 911 & 904 & 904 & 902 \\
\hline $\begin{array}{l}\text { Coarse } \\
\text { Aggregate (kg) }\end{array}$ & 708 & 708 & 708 & 708 & 708 & 692 & 692 & 702 \\
\hline $\begin{array}{l}\text { Total Binding } \\
\text { Material }(\mathrm{kg})\end{array}$ & 390 & 390 & 390 & 420 & 420 & 450 & 450 & 400 \\
\hline $\begin{array}{l}\text { Admixture Content } \\
(\%)\end{array}$ & 1.10 & 1.05 & 0.95 & 1.25 & 1.00 & 1.35 & 1.35 & 1.55 \\
\hline $\begin{array}{l}\text { Plasticizing } \\
\text { Chemical } \\
\text { Admixture (type) }\end{array}$ & $\mathrm{PC} 1$ & $\mathrm{PC} 1$ & $\mathrm{PC} 2 \mathrm{~A}$ & $\mathrm{PC} 1$ & $\mathrm{PC} 2 \mathrm{~B}$ & $\mathrm{PC} 1$ & $\mathrm{PC} 2 \mathrm{C}$ & $\mathrm{PC} 1$ \\
\hline
\end{tabular}

Flow abilities of the freshly mixed concretes were measured by means of testing of mixture consistencies by slump tests which is defined in TS EN 12350-2 [12]. The compressive strength tests were carried out on $150 \mathrm{~mm}$ cubic specimens at the ages of 7 and 28 days. Effects of plasticizing chemical admixtures on the properties of fresh and hardened concrete were investigated.

\section{RESULTS AND DISCUSSIONS}

In the experimental study flow ability of freshly mixed concrete were measured. Figure 10 presents the flow measurements of the mixtures.

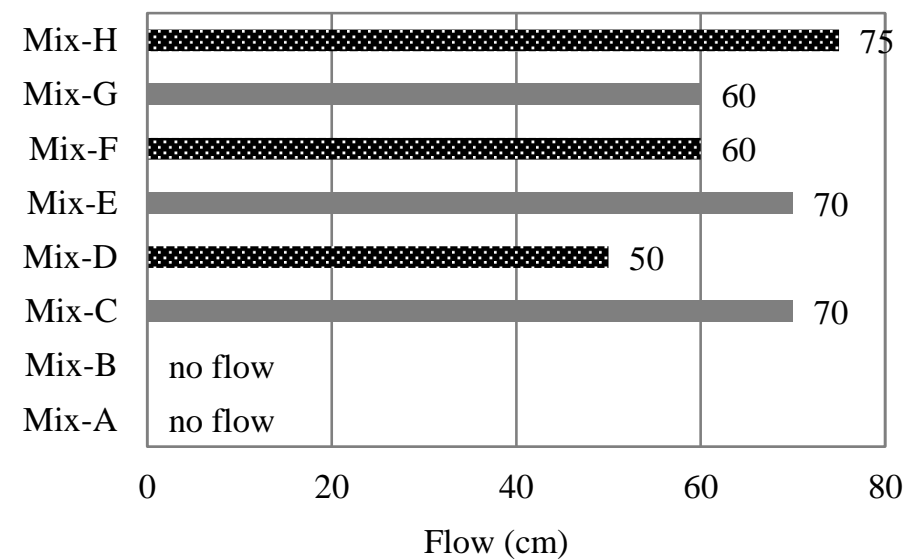

Figure 10. Flow measurements of the mixtures

Concrete mixtures Mix-A, Mix-B, Mix-D, Mix-F and Mix-H were produced by PC1 plasticizing chemical admixture and MIX-C, Mix-E and Mix-G were produced by $\mathrm{PC} 2 \mathrm{~A}, \mathrm{PC} 2 \mathrm{~B}$, and $\mathrm{PC} 2 \mathrm{C}$, respectively. For the mixtures, Mix-A and Mix-B, no flow was observed. It was attributed to the low amount of admixture in these two mixtures among the mixtures produced by PC1 plasticizing admixture. I was clear that flow values increased when the amount of admixture in the mixture increased. For example, a flow value of $70 \mathrm{~cm}$ was measured for Mix- $\mathrm{H}$ in which the admixture 
content was $6.05 \mathrm{~kg} / \mathrm{m}^{3}$ (1.55\% of total binding material). Flow test results indicated also that the composition of the admixture affected the flow values of the mixtures. For example, the flow value of Mix-C (PC2) was found to be higher than that of MIX-D (PC1), although the admixture dosage of Mix-C (0.95\%) was lower than that of Mix-D (1.25\%).

Compressive strength tests were carried out at the ages of 7 and 28 days in order to examine the hardened properties of the concrete mixtures. Figure 11 shows the compressive strength values of different mixtures produced in this experimental study.

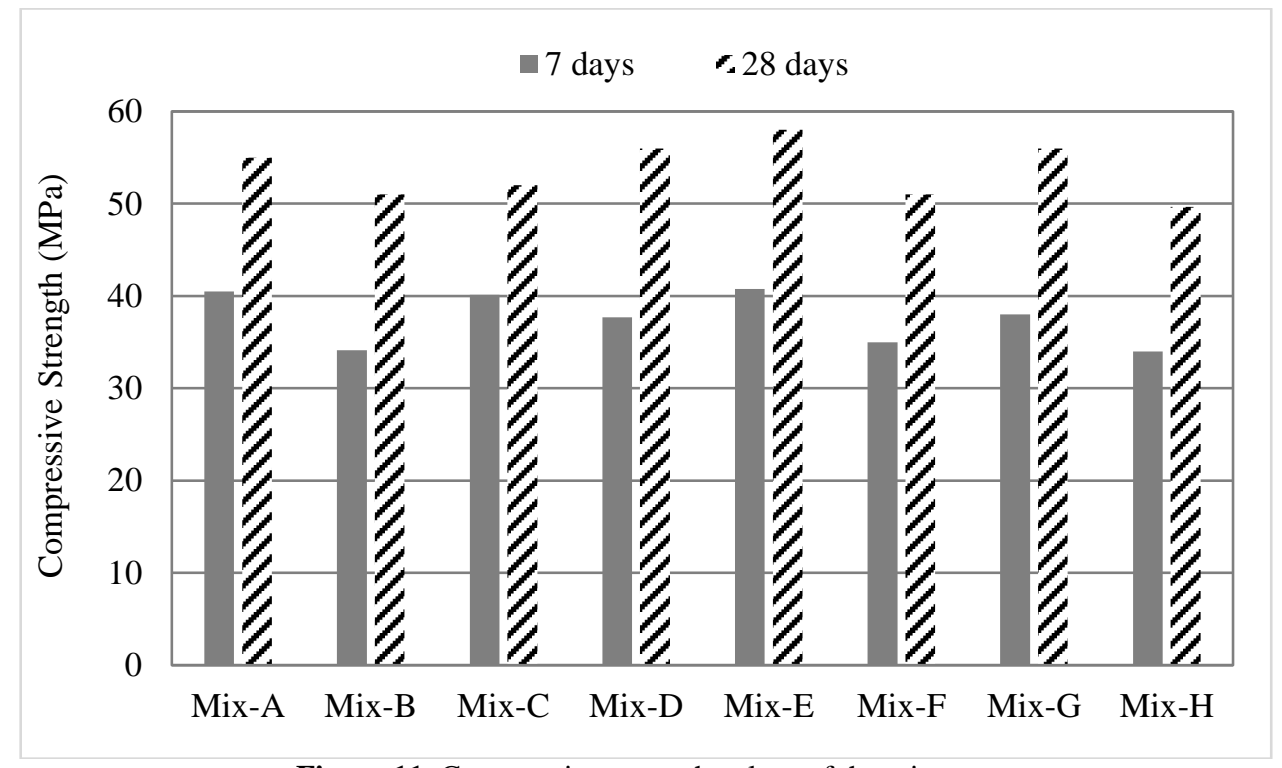

Figure 11. Compressive strength values of the mixtures

Compressive strength test results indicated that 7-days strength values ranged between 34 and $41 \mathrm{MPa}$ and 28-days strength values ranged between 51 and $58 \mathrm{MPa}$. Test results revealed that the increase in amount of slag in the amount of total binding material resulted in lower 7-days strength values. For example, the 7-days strength of Mix-B was found to be lower than that of Mix-A, although both Mix$\mathrm{A}$ and Mix-B were produced with $390 \mathrm{~kg} / \mathrm{m} 3$ of total binding material. The differences between the 7days strength and 28-days strength for Mix-A and Mix-B were found to be 14.5 and $16.9 \mathrm{MPa}$, respectively. This can be attributed the slower reaction of ground granulated blast furnace slag (GGBFS) with respect to cement. Test results indicated that the type of chemical admixtures influenced the strength values. Although Mix-B (used PC1) and Mix-C (used PC2) were produced with equal amounts of cement, slag and water, the 7-days strength values significantly different for Mix-B and Mix-C. The compressive strength value of Mix-B at the age of 7 days was $34.1 \mathrm{MPa}$ while that of Mix-C was $40.1 \mathrm{MPa}$. This can be caused by the different secondary effects of different plasticizing chemical admixtures. It was found that type of chemical admixture influenced both 7-days strength and 28-days strength even the mixtures had equal amounts of ingredients. For example, 7days compressive strength value of Mix-G was found 3.0 MPa higher than that of Mix-F, and 28-days compressive strength value of Mix-G was found 5.0 MPa higher than that of Mix-F although the amounts of constituent materials were equal to each other for the mixes Mix-F and Mix-G. This result showed that plasticizing chemical admixtures can affect both early and later age strengths of ready mixed concrete even for equal water/binder ratios.

\section{CONCLUSIONS}

In the experimental study flow ability of freshly mixed concrete and compressive strength of hardened concrete were measured. For some mixtures no flow was observed and it was attributed to the low 
amount of admixture in these mixtures. It was observed that flow values increased when the amount of admixture used in the mixtures increased. Flow test results indicated also that the composition of the admixture affected the flow values of the mixtures. Compressive strength test results revealed that the increase in amount of slag in the amount of total binding material resulted in lower 7-days strength values. This can be attributed the slower reaction of ground granulated blast furnace slag (GGBFS) with respect to cement. Test results indicated that the type of chemical admixtures significantly influenced the 7-days strength values. This can be caused by the different secondary effects of different plasticizing chemical admixtures. It was found that type of chemical admixture influenced both 7-days strength and 28-days strength even the mixtures had equal amounts of ingredients and also equal water/binder ratios. This result showed that plasticizing chemical admixtures can affect both early and later age strengths of ready mixed concrete even for equal water/binder ratios.

\section{ACKNOWLEDGEMENTS}

Authors kindly thank to Polisan A.Ş. for their material supply in order to carry out this experimental study.

\section{REFERENCES}

[1] Arioz O. Ready Mixed Concrete. CE 447 Course Class Notes, Hasan Kalyoncu University, Gaziantep, Turkey, 2017.

[2] Zongjin L. Advanced Concrete Technology. John Wiley and Sons Inc., New Jersey, 2011.

[3] Kosmatka SH, Kerkhoff B, Panarese WC. Design and Control of Concrete Mixtures. Portland Cement Association, Illinois, 2003.

[4] Collepardi M. Admixtures used to enhance placing characteristics of concrete. Cement and Concrete Composites 1998; 20: 103-112.

[5] Newman J, Choo BS. Advanced Concrete Technology: Constituent Materials. Elsevier, Burlington, 2003.

[6] Golaszewski J. Influence of cement properties on new generation superplasticizers performance. Construction and Building Materials 2012; 35: 586-596.

[7] Kovler K, Roussel N. Properties of fresh and hardened concrete. Cement and Concrete Research 2011; 41: 775-792.

[8] TS EN 197-1. Cement - Part 1: Composition, specification and conformity criteria for common cements, Ankara, 2012.

[9] TS EN 933-1:2012(EN). Tests for geometrical properties of aggregates - Part 1: Determination of particle size distribution - Sieving method, Ankara, 2012.

[10] TS 706 EN 12620+A1. Aggregates for concrete, Ankara, 2009.

[11] TS 802. Design of concrete mixes, Ankara, 2016.

[12] TS EN 12350-2. Testing fresh concrete - Part 2: Slump test, Ankara, 2010. 